\title{
Tornado Climatology of Finland
}

\author{
JENNI RAUHALA \\ Finnish Meteorological Institute, Helsinki, Finland \\ HAROLD E. BROOKS \\ NOAA/National Severe Storms Laboratory, Norman, Oklahoma \\ DAVID M. SCHULTZ \\ Centre for Atmospheric Science, School for Earth, Atmospheric and Environmental Sciences, University of Manchester, \\ Manchester, United Kingdom, and Division of Atmospheric Science, Department of Physics, University of Helsinki, \\ and Finnish Meteorological Institute, Helsinki, Finland
}

(Manuscript received 31 July 2011, in final form 8 November 2011)

\begin{abstract}
A tornado climatology for Finland is constructed from 1796 to 2007. The climatology consists of two datasets. A historical dataset (1796-1996) is largely constructed from newspaper archives and other historical archives and datasets, and a recent dataset (1997-2007) is largely constructed from eyewitness accounts sent to the Finnish Meteorological Institute and news reports. This article describes the process of collecting and evaluating possible tornado reports. Altogether, 298 Finnish tornado cases compose the climatology: 129 from the historical dataset and 169 from the recent dataset. An annual average of 14 tornado cases occur in Finland (1997-2007). A case with a significant tornado (F2 or stronger) occurs in our database on average every other year, composing $14 \%$ of all tornado cases. All documented tornadoes in Finland have occurred between April and November. As in the neighboring countries in northern Europe, July and August are the months with the maximum frequency of tornado cases, coincident with the highest lightning occurrence both over land and sea. Waterspouts tend to be favored later in the summer, peaking in August. The peak month for significant tornadoes is August. The diurnal peak for tornado cases is 1700-1859 local time.
\end{abstract}

\section{Introduction}

As late as the mid-1990s, Finnish meteorologists generally assumed that severe convective storms or tornadoes did not occur in Finland and, if they occurred, they were rare. Tornado reports were not collected, and no research on severe convective storms was published from the 1960s until recently. However, since 1997, severe thunderstorms, and especially tornadoes, have received a lot of media attention in Finland. Thus, Finnish meteorologists have started to appreciate the occurrence and threat of severe weather. This appreciation has led to several studies on severe weather in Finland: a climatology of mesoscale convective systems (Punkka and Bister

Corresponding author address: Jenni Rauhala, Finnish Meteorological Institute, Erik Palménin Aukio 1, P.O. Box 503, FI-00101, Helsinki, Finland.

E-mail: jenni.rauhala@fmi.fi
2005), a case study of a severe thunderstorm outbreak (Punkka et al. 2006), micrometeorological measurements of a microburst (Järvi et al. 2007), a severe hail climatology (Tuovinen et al. 2009), and several case studies of tornadoes (e.g., Teittinen et al. 2006; Teittinen and Mäkelä 2008; Outinen and Teittinen 2008; Rauhala and Punkka 2008). Yet, no climatology of tornadoes exists for Finland.

Historically, in Italy and France, scientific papers on tornado cases were published by the seventeenth century (Peterson 1982). The first research covering all of Europe was Wegener (1917). Estonia, the southern neighbor of Finland, has a long history in tornado research. Between the wars, tornado research was done by Johannes Letzmann (Peterson 1992, 1995) and recently by Tooming et al. (1995) and Tarand (1995). In Sweden, several case studies have been performed (Peterson 1998).

More recently, European tornado climatologies have been published for Ireland (Tyrrell 2003), the United 
Kingdom (Elsom and Meaden 1982; Reynolds 1999; Holden and Wright 2004), Lithuania (Marcinoniene 2003), and the former Soviet Union (Peterson 2000). The climatology of French tornadoes has been studied by Dessens and Snow $(1989,1993)$ and Paul (2001). Tornado statistics for Germany and Austria have been published by Dotzek (2001) and Holzer (2001), respectively. Climatologies for the Czech Republic by Setvák et al. (2003) and for Hungary by Szilard (2007) have been constructed. In southern Europe, tornado climatologies have been documented in Greece (Sioutas 2003, 2011), the Balearic Islands (Gayá et al. 2001), Spain (Gayá 2011), Portugal (Leitao 2003), and Italy (Giaiotti et al. 2007).

Despite a long history of observing tornadoes, not all European countries have a database of severe weather reports. The European Severe Weather Database (Brooks and Dotzek 2008; Dotzek et al. 2009) has improved the collection of severe weather reports from around Europe. Because many European national hydrometeorological services are actively developing their severe thunderstorm forecast and warning services (Rauhala and Schultz 2009), many countries have acknowledged that understanding the local climatology is important for forecasting.

The purpose of this article is to create a tornado climatology for Finland. The definition of a tornado, methods to collect reports, and the credibility evaluation process are discussed in section 2. Sections 3-4 summarize the geographical and intensity distributions of tornado cases, and sections 5-6 summarize the monthly and diurnal distributions. Section 7 concludes this article.

\section{Data}

This section describes the development of the Finnish tornado climatology. Because $10 \%$ of Finland is covered by freshwater and because Finland has a relatively low population density, we take care in defining the criteria for tornadoes and waterspouts. Section $2 \mathrm{a}$ addresses this issue. Then, having described our definition for a tornado, the climatology is constructed in two steps. The first step was to collect historical reports of tornadoes from archived sources such as newspapers. The second step was to collect recent reports of tornadoes in nearreal time through the Finnish Meteorological Institute (FMI). Section 2b discusses the different methods employed to compile and evaluate tornado reports in these two datasets. Finally, section $2 \mathrm{c}$ describes how the tornado intensities are assessed.

\section{a. Tornado definition and criteria}

The Glossary of Meteorology (Glickman 2000) defines a tornado as "a violently rotating column of air, in contact with the ground, either pendant from a cumuliform cloud or underneath a cumuliform cloud, and often (but not always) visible as a funnel cloud." Forbes and Wakimoto (1983) suggested that a vortex would be classified as a tornado if it were strong enough to cause at least F0 (Fujita 1981) damage. These definitions were adopted in the United States where all tornadoes have been classified by the Fujita scale ( $F$ scale), even if there were no damage. Since 2007, tornado intensity has been rated in the United States with the Enhanced Fujita scale (EF scale; Doswell et al. 2009). On the other hand, waterspouts that do not hit land are not classified as tornadoes in the United States. This definition would be a serious restriction for Finland, where almost 188000 lakes cover the landscape. In this work, the following tornado definition is used: A tornado is a vortex between a cloud and the land or water surface, in which the connection between the cloud and surface is visible, or the vortex is strong enough to cause at least FO damage. This definition allows all waterspouts to be included in the definition of a tornado. This is consistent with the Glossary of Meteorology (Glickman 2000) definition, which defines a waterspout as "any tornado over a body of water." Also, tornadoes over land that do not cause damage, but have a visible connection between ground and the cloud base, are included.

In this article, we will also make use of the concept of a tornado case. In one tornado case, there might be many tornadoes. For example, several tornadoes might occur near each other (e.g., within the same storm, along the same boundary, etc.), but this would be classified as one tornado case. This concept improves the database because, in several waterspout cases, for example, the exact number, location, or timing of each individual tornado is not known. Because waterspouts often occur in groups of 5-20 single tornadoes, if each were recorded as an individual event, the monthly, diurnal, intensity, and geographical distribution of waterspouts would dominate the database of all tornadoes.

On the other hand, if tornadoes are known to occur in separate storms, or the starting points of the successive tornadoes can be resolved, they are considered to be separate cases. There is often not enough information to split a report into several cases. Particularly in the historical dataset, the path length would often suggest a series of tornadoes, but the event is still recorded as one case due to the lack of detailed information on damage tracks. The problem of distinguishing between long-track tornadoes and a series of short-track tornadoes is discussed by Doswell and Burgess (1988). The starting point of the first tornado path in each event characterizes the case on geographical maps. In several instances, the same tornado moves over both water and 
land surfaces. If a tornado is first observed over land, it is classified as a tornado over land. If it is first observed over water, it is classified as a tornado over water. From here on, "tornado over water" and "waterspout" will be used interchangeably. A tornado day in this article is defined as a day with at least one tornado case. A tornado report is the original tornado observation (from media, public, etc.); several tornado reports may exist for each tornado case.

\section{b. Collecting tornado reports}

Because the methods of collection, evaluation, and classification of tornado reports have changed over time, the tornado climatology of Finland comprises two datasets. The historical dataset covers 1796-1996 when no systematic tornado documentation was maintained at FMI. The recent dataset covers 1997-2007 when FMI has been actively collecting information on tornadoes in Finland.

The tornado reports in the 1796-1996 historical dataset were collected through five different approaches. First, most of the reports in the historical dataset come from old newspaper articles. The oldest articles were found in the microfilm archives and digital collections of major newspapers (Finlands Allmänna Tidning, Ilmarinen, Keski-Suomi, Porin Kaupungin Sanomia, Sanomia Turusta, Tapio, Vesta Nyland, Abo Tidningar, and Abo underrättelser) in the National Library of Finland. Second, FMI's archives contained an unsystematic collection of weather-related newspaper clips and of FMI-related articles from the 1990s. The more recent newspaper articles were from Aamulehti, Borgåbladet, Etelä-Saimaa, Etelä-Suomi, Helsingin Sanomat, Iitinseutu, Ilta Sanomat, Kainuun Sanomat, Kaleva, Karjalainen, Keskisuomalainen, Kuorevesi-Mänttä-Vilppula, Lapin Kansa, Maakansa, Savon Sanomat, Suomenmaa, Suur-Keuruun Sanomat, Syd-Österbotten, Turun Sanomat, Uusi Aura, and Uusi Suomi. Altogether, the archived and more recent newspaper articles resulted in 98 tornado cases. Third, 17 tornado cases were obtained from the general public during the 1970s and 1980s and were documented in the forecasters' notebook-an unsystematic collection of reports of strange phenomena received from the general public. Fourth, 12 cases, mainly from the 1930s, come from published meteorological descriptions (Keränen 1930; Simojoki 1931, 1935; Angervo 1949; Rossi and Franssila 1960). Fifth, two tornado cases are from Wegener's (1917) book on European tornadoes. Because of the lack of detailed information on the tornado cases, these historical data did not go through an extensive quality control and most of the reported tornado cases were included in the statistics. Few cases were rejected because the available information on the
TABLE 1. Credibility categories of tornado reports. The report is attributed to the highest class where any of the criteria are satisfied.

\begin{tabular}{ll}
\hline Category & \multicolumn{1}{c}{ Criteria } \\
\hline Confirmed & $\begin{array}{l}\text { A photograph or videotape of a tornado } \\
\text { Damage survey indicates tornado damage }\end{array}$ \\
Probable & $\begin{array}{l}\text { Credible eyewitness observation of a tornado } \\
\text { Credible eyewitness report of typical tornado } \\
\text { damage } \\
\text { A photograph of a typical tornado damage }\end{array}$ \\
Possible & $\begin{array}{l}\text { No eyewitnesses } \\
\text { Cause of the damage is not confirmed by } \\
\text { the observations of an eyewitness }\end{array}$ \\
\hline
\end{tabular}

event was too limited. This process resulted in 129 tornado cases.

In the recent 1997-2007 dataset, most of the preliminary reports were obtained from the general public. The main source for these reports was through a tornado observation report form placed on the FMI Web site (http://www.fmi.fi) since 1998. In addition, preliminary reports were received from the general public by phone and by e-mail. Reports from news media were collected also, including related newspaper articles and reporter information. Data from different sources were gathered into tornado cases and, in all except a few cases, eyewitnesses were interviewed. Photos and videos of the tornado and its damage were collected and, in some cases, a damage survey was performed.

The credibility of a report was evaluated in the recent 1997-2007 dataset based on the observed information available on the event. Each case was categorized as confirmed, probable, or possible (Table 1). Similar definitions have been used in Canada to evaluate tornado reports (Newark 1984). Only confirmed and probable tornado cases were accepted into the recent dataset, which has now become the official tornado dataset for Finland. Radar pictures were also studied for the tornado cases of the last $8 \mathrm{yr}(2000-07)$. If there was no radar echo during or after a reported tornado, and satellite pictures did not show cloudiness, the case was not included in the recent dataset. This process resulted in 169 tornado cases.

The historical dataset is undoubtedly incomplete, particularly the records of weak tornado cases, as indicated by the change in number of tornado cases per decade (Fig. 1a). Before the 1930s, there are only a few, if any, known reports per decade. In the 1930s, 30 tornado cases (10 of which had a F2 or greater tornado; Table 2) affected Finland, causing two deaths, several injuries, and vast material damage, which awoke the interest of meteorologists during that period. Both the attention paid to tornadoes and the availability of documented reports are reflected in the statistics with a larger number of 
a)
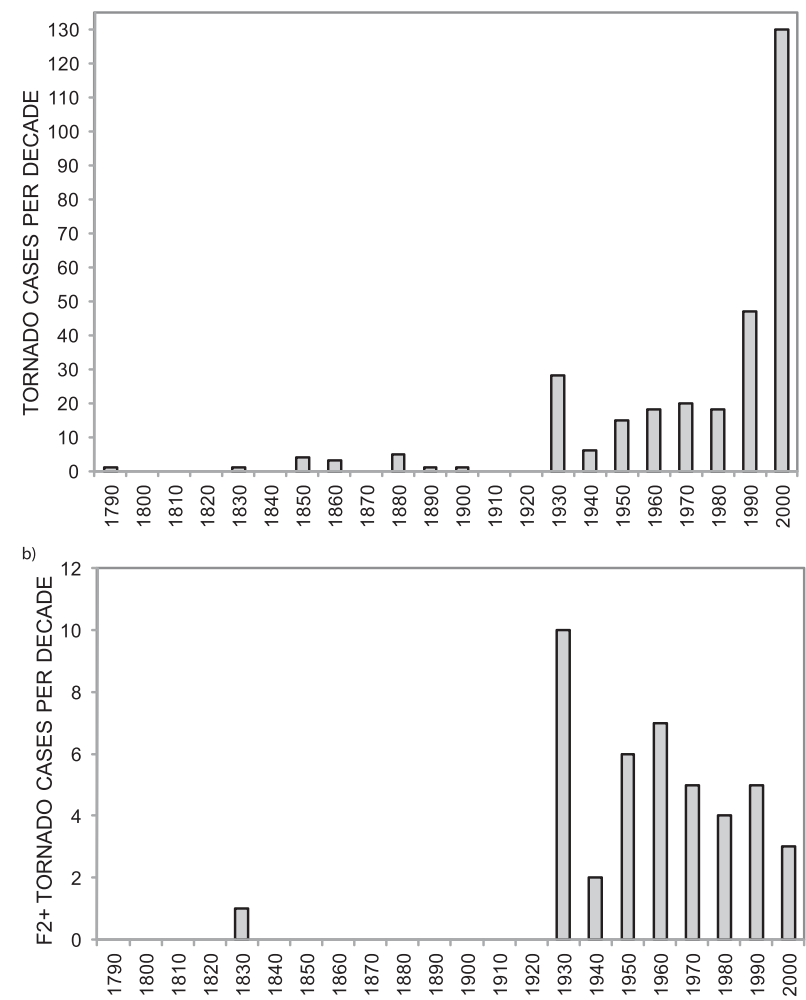

FIG. 1. (a) All and (b) significant tornado cases per decade in Finland. The last decade includes only 2000-07.

reports during the 1930s, 1990s, and 2000s. We hypothesize that the movie Twister and an increase in television documentaries on tornadoes led to an increased awareness among the public about tornadoes in the late 1990s. Both the increased awareness and the onset of active collecting of tornado reports show in the statistics, as during 1997-2007, a mean of 14 confirmed and probable tornado cases occurred each year, with a mean of 11 tornado days. The tornado database is likely to be more consistent over time for the more intense tornadoes (e.g., Brooks and Doswell 2001; Verbout et al. 2006). During 1930-2007, significant-tornado (F2 or stronger; Hales 1988) cases occurred on average every second year, but with a slight downward trend (Fig. 1b).

\section{c. Estimating tornado intensity}

The tornado intensity assessment is based on a damage survey, photographs, or eyewitness description of the damage. The estimate is based on the Fujita scale (Fujita 1981) and guidance tables for assigning tornado damage to buildings (Minor et al. 1977, their Table 4; Bunting and Smith 1993, their appendix C). The estimates were made by a single person (the first author), so the data should not contain some of the inhomogeneities discussed by Doswell and Burgess (1988), although systematic biases may occur. The information available on events in the historical dataset is often so limited that an accurate $F$-scale estimate cannot be assigned. Instead, for the historical dataset, the $F$-scale estimate is the minimum intensity that could cause the described or photographed damage. In this article, tornadoes without damage are unrated on the Fujita scale. Only $22 \%$ of the cases in the historical dataset were unrated, whereas $56 \%$ of the cases in the recent dataset were unrated.

There is uncertainty in estimating the intensity of tornadoes using the $F$ scale. Damage is not equivalent to intensity because the damage depends, not only upon the wind speed, but also upon the object receiving damage (Doswell and Burgess 1988; Doswell 2007). Terrain, building codes, debris, speed of the tornado, or rapidly fluctuating winds can contribute to the damage and affect the estimate of intensity. For example, tornadoes without damage are often classified as weak, although the true intensity could not be determined. Doswell and Burgess (1988) argued that many tornadoes have inappropriate $F$ ratings, perhaps by two categories or more. On the other hand, the $F$ scale is largely based on damage to buildings, and the construction standards in Finland, as well as Europe as a whole, may differ from those in the United States (e.g., Feuerstein et al. 2011).

\section{Geographical distribution}

Tornado cases in our database are most frequent in eastern and south-central Finland, as well as over the southern and southwestern seawaters (Fig. 2a). The occurrence is lowest in Lapland in northern Finland and in some inland areas of western Finland. The occurrence of waterspout cases is high over the southern and southwestern seawaters, but also in the lakes of central Finland. If each waterspout were recorded separately instead of grouped into tornado cases, the frequency over the seas would be much larger. The large number of lakes and the large land area they cover helps to explain that $20 \%$ of all tornado cases in this database spend part of their time over land and part of their time over water.

The concentration of cases in eastern Finland is more evident when only the significant tornado cases are considered (Fig. 2b). The annual probability of significanttornado cases was calculated during 1930-2007 because significant tornadoes are less sensitive to changing reporting practice with time (e.g., Brooks and Doswell 2001; Verbout et al. 2006). The climatological probability of at least one significant tornado within an $80 \mathrm{~km} \times$ $80 \mathrm{~km}$ area during a year in several areas in centralsouthern and eastern-central Finland is 5\%-7\%. This means that an F2 or stronger tornado occurs in the area 
TABLE 2. Significant (F2 and greater) tornado cases in Finland.

\begin{tabular}{|c|c|c|c|c|c|c|c|}
\hline Date & Time (LT) & Location & $\begin{array}{c}\text { Damage path } \\
\text { width }(\mathrm{m})\end{array}$ & $\begin{array}{l}\text { Damage path } \\
\text { length }(\mathrm{km})\end{array}$ & Intensity & $\begin{array}{l}\text { No. of } \\
\text { fatalities }\end{array}$ & $\begin{array}{l}\text { No. of } \\
\text { injuries }\end{array}$ \\
\hline 1 Jul 1838 & $1600-1700$ & Turku & $25-35$ & & $\mathrm{~F} 2$ & & \\
\hline 27 May 1930 & $1240-1250$ & Paltamo & & $3-4$ & $\mathrm{~F} 2$ & & \\
\hline 29 Jun 1931 & $1600-1800$ & Vehmersalmi & 60 & 2 & $\mathrm{~F} 2$ & & \\
\hline 4 Aug 1932 & 1500 & Nurmijärvi & $400-500$ & 14 & F3 & 1 & 1 \\
\hline 4 Aug 1932 & 1530 & Hausjärvi & $100-150$ & 39 & $\mathrm{~F} 3$ & & \\
\hline 6 Aug 1932 & 1700 & Rautavaara, Nurmes & $100-150$ & 7 & $\mathrm{~F} 2$ & & \\
\hline 6 Aug 1932 & 1915 & Kuopio & $40-50$ & 4 & $\mathrm{~F} 2$ & & \\
\hline 11 Sep 1932 & 1700 & Kannus & 100 & 10 & $\mathrm{~F} 2$ & & \\
\hline 12 Jul 1933 & 1400 & Toholampi & 2000 & 6 & $\mathrm{~F} 3$ & & \\
\hline 11 Jul 1934 & 1125 & Kiuruvesi & 200 & 15 & $\mathrm{~F} 4$ & 1 & \\
\hline $11 \mathrm{Jul} 1934$ & 1330 & Pulkkila & 200 & 10 & $\mathrm{~F} 3$ & & 1 \\
\hline 9 Aug 1948 & 1200 & Maaninka & & & $\mathrm{F} 2$ & & \\
\hline 1 Oct 1949 & 1615 & Joutsa & $100-150$ & & $\mathrm{~F} 2$ & & \\
\hline 29 Jul 1954 & 1200 & Hamina, Vehkalahti, Anjalankoski & & 20 & $\mathrm{~F} 2$ & & \\
\hline 9 Jun 1956 & & Nilsiä, Juankoski & & & $\mathrm{F} 2$ & & \\
\hline 27 Jul 1957 & $1800-1900$ & Imatra & $2500-3000$ & 10 & $\mathrm{~F} 2$ & 3 & \\
\hline 27 Jul 1957 & $2000-2100$ & Luhanka & & $25-30$ & $\mathrm{~F} 2$ & & \\
\hline 27 Jul 1957 & & Karvia & & & $\mathrm{F} 2$ & & \\
\hline $10 \mathrm{Jul} 1958$ & 1500 & Polvijärvi & & & $\mathrm{F} 2$ & & \\
\hline 1 Aug 1961 & & Loviisa & 250 & & $\mathrm{~F} 2$ & & \\
\hline 1 Aug 1961 & & Orimattila, Hollola, Lammi & & & $\mathrm{F} 2$ & & \\
\hline 29 Jun 1967 & Evening & Vieremä & 100 & & $\mathrm{~F} 2$ & & \\
\hline 26 Jul 1967 & 0830 & Nurmo & & 1.5 & $\mathrm{~F} 2$ & & \\
\hline 4 Aug 1967 & & Uusikaarlepyy & 2000 & $7-8$ & $\mathrm{~F} 2$ & & \\
\hline 26 Aug 1967 & 1400 & Kaavi & 300 & & $\mathrm{~F} 2$ & & \\
\hline 7 Sep 1967 & Evening & Suomussalmi & & & $\mathrm{F} 2$ & & \\
\hline 8 Jul 1972 & Evening & Imatra, Joutseno, Puumala & & & $\mathrm{F} 2$ & 1 & 1 \\
\hline 12 Sep 1974 & 0900 & Pyhtää, Kotka & 50 & & $\mathrm{~F} 2$ & & 1 \\
\hline 15 Aug 1975 & 1750 & Orimattila, Iitti, Kuusankoski & 150 & 29 & $\mathrm{~F} 2$ & & 1 \\
\hline 30 Aug 1975 & 1035 & Vantaa & 50 & 1 & F3 & & \\
\hline 27 Jun 1976 & 1200 & Leppävirta & 500 & 2 & $\mathrm{~F} 2$ & & \\
\hline 11 Aug 1985 & 1330 & Liminka, Lumijoki & $2000-3000$ & 20 & $\mathrm{~F} 2$ & & \\
\hline 7 Jul 1988 & 1350 & Lieto & & 0.5 & $\mathrm{~F} 2$ & & \\
\hline 22 Jul 1988 & 1630 & Turku & & & $\mathrm{F} 2$ & & \\
\hline 3 Aug 1989 & 1800 & Padasjoki & 200 & & $\mathrm{~F} 2$ & & \\
\hline 28 Aug 1994 & 0600 & Ylivieska & 150 & 0.35 & F3 & & \\
\hline 15 Jun 1995 & 1730 & Närpio & & & $\mathrm{F} 2$ & & \\
\hline 23 Jun 1997 & 1805 & Lieksa & 300 & 1.2 & $\mathrm{~F} 2$ & & \\
\hline 12 Aug 1997 & 1800-1900 & Kaustinen & 150 & 1 & $\mathrm{~F} 2$ & & \\
\hline 12 Jun 1998 & $1515-1540$ & Mikkeli & 330 & 8.6 & $\mathrm{~F} 2$ & & \\
\hline 15 Jul 2000 & 1800 & Jämsänkoski & 50 & 15 & $\mathrm{~F} 2$ & & \\
\hline 9 Aug 2001 & 1900 & Rautavaara & 150 & 1 & $\mathrm{~F} 2$ & & \\
\hline 20 Aug 2004 & $1655-1720$ & Polvijärvi, Kontiolahti & & 20.2 & $\mathrm{~F} 2$ & & \\
\hline
\end{tabular}

of maximum probability once every $14-20 \mathrm{yr}$. The belt of highest risk extends from the coast of the Gulf of Finland over central Finland to the Gulf of Bothnia.

The geographical distribution of tornado cases in Finland is similar to the geographic distribution of thunderstorm days (Fig. 2a, lightning data adapted from Mäkelä et al. 2011, their Fig. 2b), although cloud-toground lightning flash rate itself is not a good indicator of tornado occurrence (e.g., MacGorman et al. 1989; Perez et al. 1997; Teittinen and Mäkelä 2008). Indeed, some tornadoes in Finland have been observed without cloud-to-ground lightning (e.g., Rauhala and Punkka 2008). In southern Finland, where the yearly mean cloudto-ground flash density is low (Tuomi and Mäkelä 2008; Mäkelä et al. 2011, their Fig. 1b), tornado cases and significant tornado cases are relatively frequent. However, cloud-to-ground flash density is only one measure of the location of deep moist convection. Although the basic conditions necessary for tornadoes and cloud-to-ground lightning occurrence are not the same, both phenomena require the existence of a convective cloud and a strong updraft. Therefore, the geographical distribution of 
a)

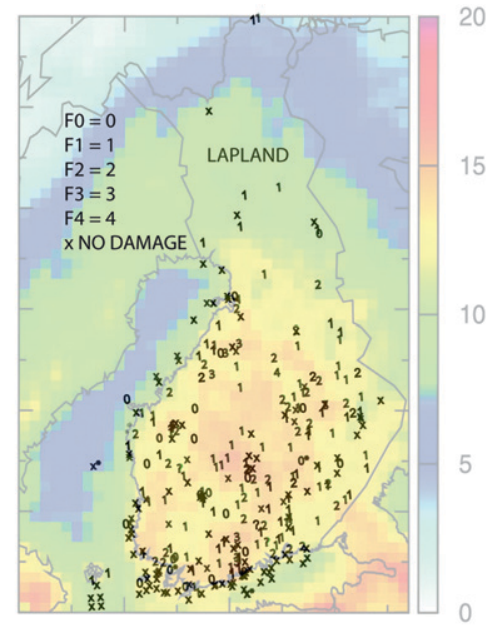

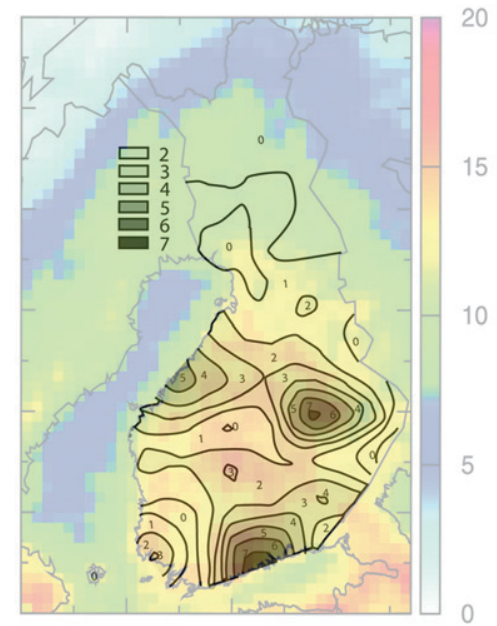

c)

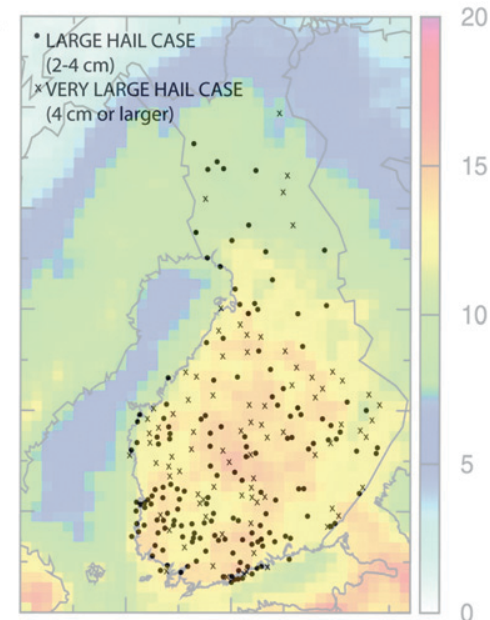

FIG. 2. Geographical distribution of (a) all tornado cases during 1796-2007 in Finland, plotted by the $F$ scale as in the legend. (b) Annual probability (in percent) of at least one significant tornado in an $80 \mathrm{~km} \times 80 \mathrm{~km}$ area based on the 1930-2007 statistics. (c) Geographical distribution of severe hail cases in Finland during 1930-2006 from Tuovinen et al. (2009). All figures are overlaid on average annual number of thunderstorm days for Finland from Mäkelä et al. (2011). The units are thunderstorm days per year.

thunderstorm days can be compared to the tornado occurrence. The frequency of thunderstorm days in Finland is highest in central Finland, where the yearly average is around 15 days (Fig. 2). This area coincides quite well with the relatively frequent areas for significant tornado cases. In Lapland, where the tornado cases are relatively infrequent, 4-11 thunderstorm days occur per year. Thus, the average number of thunderstorms days seems to correspond roughly to the significant tornado case frequency.

Also, severe hail (Fig. 2c, hail data adapted from Tuovinen et al. 2009) seems to have a similar geographical distribution as tornado cases in Finland, although a few of the cases in the two datasets are from the same events. The main differences in the geographical distributions are the larger number of severe hail cases compared to tornado cases in agricultural areas in western Finland, and the smaller number of severe hail cases compared to tornado cases over coastal waters and in southeast Finland, where 30\% of the surface are lakes. The likelihood of severe hail events being recorded over agricultural areas and unlikelihood of them being recorded on water surfaces compared to tornadoes may partly explain these differences. Despite these differences, the similarity of geographical distributions of tornado cases and large hail motivates the question of whether geographically favored locations exist for the most severe convective weather in Finland.

Unfortunately, we have few hypotheses for why such a distribution of tornadoes, if representative of a larger sample, would occur. An explanation from the orography is not apparent. Finland is a relatively flat country, where only small areas of central Finland and northern Finland have an elevation of more than $200 \mathrm{~m}$ above sea level, and tornado occurrence does not seem to be related to elevation or gradients in elevation. The landsea- and land-lake-induced boundaries near the coast and near lakes in eastern Finland may provide a favorable environment for tornadogenesis, but that hypothesis is not explored within this article.

The small sample size of tornado cases in Finland at any given location allows only an estimate of the broad spatial patterns of tornado occurrence (e.g., Doswell 2007). Also, because of the sparse population of Finland (an average of 16 inhabitants per square kilometer, equal to that of Colorado), tornadoes are very likely underreported and may be biased toward population centers. Indeed, more tornado reports are received in areas of regionally high population density, especially for weak tornadoes. In Lapland in the northern part of Finland, where the population density is much lower (two inhabitants per square kilometer, equal to that of Wyoming), the number of known tornado events is small, even though in southern and central Lapland there is an average of 8-11 thunderstorm days annually (Mäkelä et al. 2011).

\section{Intensity distribution}

Most (86\%) of the 298 tornado cases in our database were of F1 intensity or less (Fig. 3). A total of 43 significant tornado cases have been observed (Table 2). There are differences in the intensity distribution between the historical and recent datasets. Specifically, 


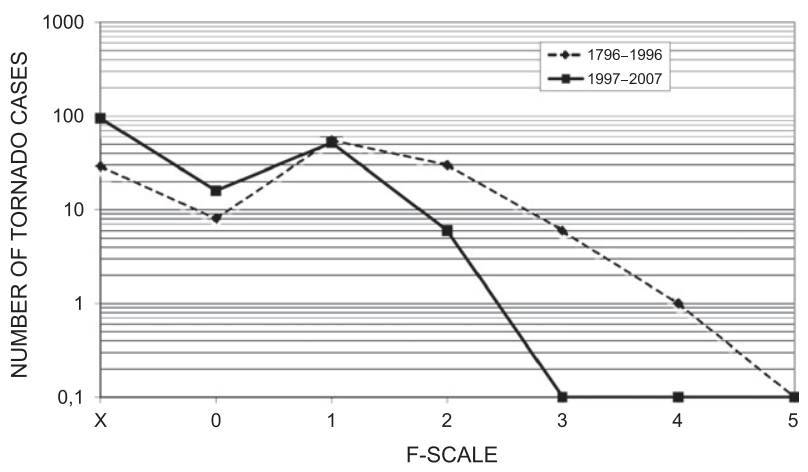

FIG. 3. Number of tornado cases both in historical (1796-1996) and more recent (1997-2007) datasets by the $F$ scale.

$29 \%$ of the tornado cases from 1796-1996 were significant tornado cases, but only $4 \%$ of the tornado cases from 1997-2007 were significant. The smaller percentage of significant tornado cases in the recent dataset can be explained by the more efficient collection of tornado reports, especially for F1 and weaker tornadoes, similar to that seen in the United States (Brooks and Doswell 2001; Verbout et al. 2006), and the fewer number of intense tornado cases in the shorter 1997-2007 period (Fig. 3). Because stronger tornadoes typically have larger effects on society and influence larger areas (Brooks 2004), observations of the more intense tornadoes tend to be less sensitive to variations in reporting practice over time (e.g., Verbout et al. 2006), explaining the large proportion of significant tornado cases in the historical dataset.

There have been only six F3 cases, one F4, and no F5s recorded in our database. The F4 tornado occurred on 11 July 1934 at Kiuruvesi in central Finland. By comparison, F4 tornadoes have been observed in several other European countries: Estonia (Tooming 2002), Germany (Dotzek 2001), and the Czech Republic (Setvák et al. 2003). In France, a few F5 tornadoes have been observed (Paul 2001). As in Finland (Fig. 3), a relatively small number of tornadoes in these countries are strong. The decline with intensity is similar to that seen in Brooks and Doswell (2001) and Dotzek et al. (2003). When greater attention is put into collecting reports or there is greater public awareness of tornadoes, as in Ireland (Tyrrell 2003), the relationship is closer to being log-linear. The impact of the onset of active collecting of reports can be also seen in Finland, where the number of weak tornado cases has increased in the recent dataset compared to the historical dataset (Fig. 3). This underreporting of weaker tornadoes has been observed in other countries (e.g., Germany, France, etc.).

In east-central Finland, the fraction of tornado cases that were significant was higher than elsewhere in
Finland. In Lapland and in large parts in western Finland, significant tornadoes have not been observed. However, because the $F$-scale rating depends on the damage the tornado causes, tornadoes in rural areas may be underrated (e.g., Doswell and Burgess 1988). Most tornadoes and waterspouts occurring at the coast were F1 or weaker. If all waterspouts were recorded as single events, the portion of nondamaging or weak tornado cases would be higher, especially in the recent dataset.

\section{Monthly distribution}

Tornadoes have only been observed in Finland from April to November, with almost three quarters of tornado cases $(73 \%)$ occurring during the warmest months in July and August (Fig. 4a). In comparison, cloud-toground lightning may occur in Finland from April to November (Tuomi and Mäkelä 2008), with the cloud-toground flash rate the highest in continental Finland in July and highest over the seas in July and August (Tuomi and Mäkelä 2007). The majority (94\%) of severe hail cases in Finland occur between June and August, with July being the peak month (Tuovinen et al. 2009).

Based on the 1997-2007 statistics, the mean number of tornado days by month is 1 in June, 5 in July, 4 in August, and 1 in September. Days with at least three tornadoes have been observed from July to October (Fig. 4b). For all tornado cases that start on the land, the maximum is in July (Fig. 4c). Of all tornado cases in July, more than half $(54 \%)$ are weak and start on land. The maximum for significant tornadoes is in August when 17\% of all observed tornado cases are significant (Fig. 4d). Days with at least two significant tornado cases have been observed only in July and August.

Waterspout cases tend to occur toward late summer compared to all tornado cases (Fig. 4c). Therefore, if each waterspout were recorded as a single case instead of grouping them into tornado cases, the monthly distribution of tornado cases in Finland would shift more toward late summer and early autumn. The maximum number of waterspout cases in our database occurs in August when $53 \%$ of the tornado cases start over water, although the maximum percentage of waterspout cases occurs in October when $83 \%$ of the tornado cases start over water. In July, the peak month in Finland for tornado cases, only $36 \%$ of tornado cases are waterspouts. There are only a few known waterspout cases in May, June, October, and November. This is consistent with the cold sea surface temperatures in the early summer being less favorable for convection than the warmer temperatures that occur in the late summer.

Some minor differences in the monthly distribution between different geographical locations can be found 


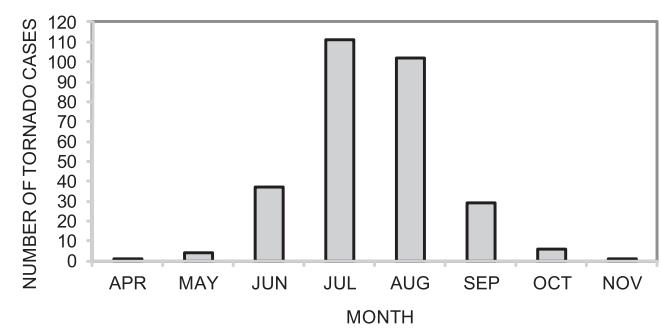

c)

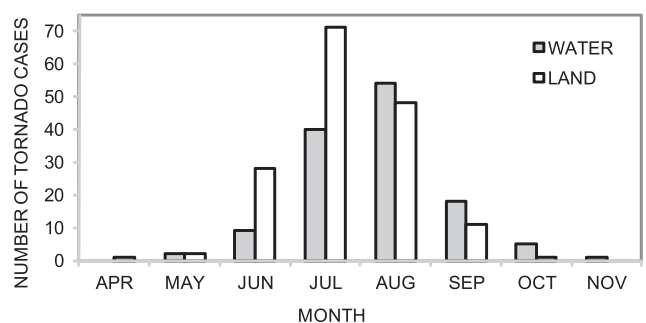

b)

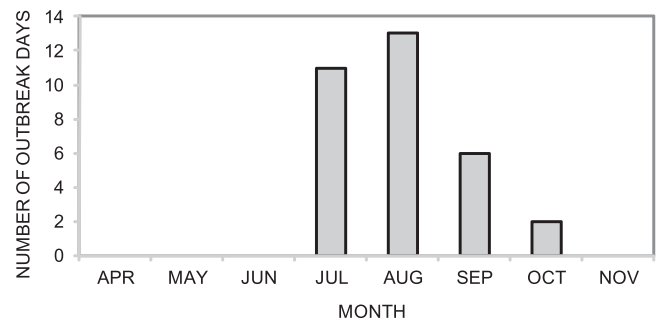

d)

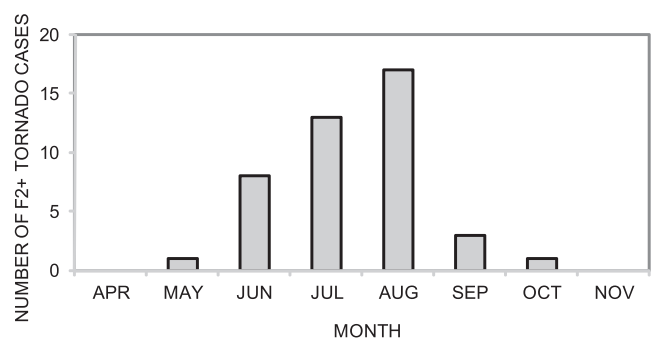

FIG. 4. (a) Monthly distribution of all tornado cases in Finland in 1796-2007. (b) Distribution of days with at least three tornado cases. (c) Distribution of tornado cases over land and water surface. (d) Monthly distribution of significant $(\mathrm{F} 2+)$ tornado cases.

in our database, although the small sample size affects the credibility of the interpretation (e.g., Doswell 2007). In western inland areas, tornado cases seem to occur mostly in July and August; in the east, they occur during the whole season. Most tornado cases offshore occur in August or September, and only a few rare events are known to occur in June.

As in Finland, tornadoes in neighboring Estonia (Tarand 1995) and Sweden (Peterson 1998) occur most frequently during July and August. In central European countries, the peak occurs earlier in the summer: in Germany and in Austria in July (Dotzek 2001; Holzer 2001) and in the Czech Republic and Hungary between May and July (Setvák et al. 2003; Szilard 2007). In Mediterranean countries, the peak is in late summer or autumn (e.g., Paul 2001; Gayá et al. 2001; Sioutas 2003, 2011; Giaiotti et al. 2007; Gayá 2011). Fujita (1973) found that July and August are the peak months for tornadoes from northern Russia to Germany, France, and northern Italy, whereas, in other parts of western and southern Europe, the peak moves toward the autumn. In the United States, the peak frequency for tornadoes is in May and June (Verbout et al. 2006).

\section{Diurnal distribution}

The tornado cases that had sufficient information on time of occurrence were placed in 2-h bins in local standard time (LT); 0500-0659, 0700-0859 LT, etc. Most of the tornado cases in our database occurred between
0900-2059 LT (Fig. 5a). There were only 10 tornado cases at night (between 2100 and 0659 LT), and no cases between 0100 and 0459 LT. The diurnal distribution of waterspout cases was more evenly spread throughout the day than tornado cases over land (Fig. 5b). Most $(69 \%)$ of the tornado cases over land occurred in the late afternoon and evening, between 1500 and 2059 LT, with a peak at 1700-1859 LT, whereas waterspout cases peaked at noon (Fig. 5b). If single waterspouts were recorded separately instead of grouping them into tornado cases, the diurnal maximum of tornadoes in Finland would have two peaks, one before noon and one in the afternoon.

The afternoon maximum in tornado cases is consistent with the diurnal cycle of thunderstorms in Finland, although the diurnal maximum in cloud-to-ground flash rate in mainland Finland typically peaks around 1500 1659 LT (Tuomi and Mäkelä 2008), two hours before the maximum of tornado cases. In comparison, large hail (2-3.9 cm in diameter) is most frequent between 1400 and $1800 \mathrm{LT}$ and very large hail (4 $\mathrm{cm}$ or larger) between 1600 and 2000 LT (Tuovinen et al. 2009). Tuovinen et al. (2009) speculated this shift to be related to delayed initiation of convection in slightly capped environments, which favor the most intense updrafts. We speculate that capping inversions may occur in some of the tornado situations in Finland, which would explain the later maximum of tornado cases compared to the cloud-to-ground flash-rate maximum. Similar diurnal distributions of tornadoes as in Finland occur in France (Dessens and Snow 
a)
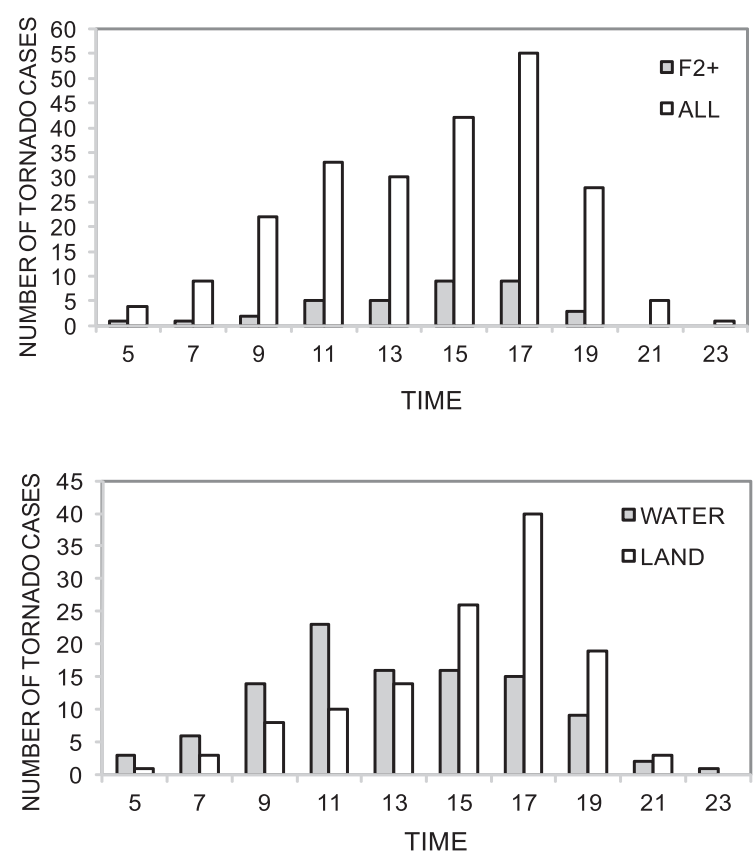

FIG. 5. Diurnal distribution of (a) all tornado cases and significant tornado cases and (b) tornado cases over water and land surface in Finland. One column indicates a 2-h period 0500-0659, 0700-0859 LT, etc. There are no tornado cases recorded between 0100 and 0459 LT.

1989), the United States (Kelly et al. 1978), and Germany (Dotzek 2001), for example.

The observed diurnal cycle of waterspout cases in Finland with a noon peak is similar to that observed by Dotzek et al. (2010) with waterspouts near the German coast at the North Sea and Baltic Sea. Distributions with three maxima-two higher peaks near noon and in the late afternoon, and a lower peak in morning - have been observed by Golden (1973) with waterspouts in the Lower Florida Keys and by Sioutas (2011) in Greece (both tornadoes and waterspouts). A possible explanation for the more evenly spread diurnal distribution of tornado cases over water compared to tornado cases over land is that the warm water surface may be a favorable location for the development of convection at any time of the day or night. Accordingly, the cloud-toground flash rate over the sea is somewhat more evenly distributed throughout the day than over land areas, but there is still a distinct afternoon maximum and minor morning maximum (Tuomi and Mäkelä 2008). Although the diurnal cycle of thunderstorms over water likely has a large influence on waterspout occurrence, the lack of tornado reports at night may also be because of darkness (in the late summer) or the smaller number of people outdoors.

\section{Conclusions}

This study summarizes the tornado climatology of Finland derived from 298 observed tornado cases during 1796-2007. The reports are collected and evaluated, resulting in two datasets: a historical dataset from 17961996 with 129 cases and a recent dataset from 1997-2007 with 169 cases. The number of tornado cases in our database is highest from the area extending from southern and southwestern seawaters to eastern Finland. The region of highest frequency of significant tornado cases extends from the Gulf of Finland to the Gulf of Bothnia. The geographical distribution of weak tornado cases shows higher concentrations of reports near densely populated areas, suggesting population bias and underreporting of weak tornadoes in sparsely populated areas.

Likely underreporting of weak tornadoes can also be seen in the historical dataset when comparing the intensity distribution of the historical and recent datasets. Whereas in the historical dataset, $29 \%$ of tornado cases were significant, in the recent dataset only $4 \%$ were significant. In the recent dataset, the large number of weak tornado cases is the result of an efficient collection of reports, whereas significant tornadoes are more likely to be independent of the efforts put into collecting reports. Altogether, $14 \%$ (43 cases) of all recorded tornado cases in Finland are significant. The strongest documented tornado is of F4 intensity.

In our database, an average of 14 tornado cases occurs every year in Finland from April to November. Coincident with the highest lightning occurrence both over land and sea, the peak months for tornado cases are July and August. August is the peak month for both waterspout cases (53\% of all August tornado cases) and significant tornado cases $(17 \%)$, whereas typically $(52 \%)$ July tornado cases are weak tornado cases over land. Most tornado cases over land occur between 1500 and 2059 LT, whereas tornado cases over water tend to occur more equally throughout the day.

Acknowledgments. We thank Sylvain Joffre (Finnish Meteorological Institute) for his comments on an earlier version of the manuscript and Pentti Pirinen (Finnish Meteorological Institute) for providing data for Fig. 2b. Partial funding for Schultz comes from Vaisala Oyj and Grant 126853 from the Academy of Finland.

\section{REFERENCES}

Angervo, J. M., 1949: Pyörremyrskyt lokakuun 1. P:nä 1949 (Tornadoes on 1st October 1949.) IK, kuukausikatsaus, 43 (10), p. 4.

Brooks, H. E., 2004: On the relationship of tornado path length and width to intensity. Wea. Forecasting, 19, 310-319. 
— , and C. A. Doswell III, 2001: Some aspects of the international climatology of tornadoes by damage classification. Atmos. Res., 56, 191-201.

— and N. Dotzek, 2008: The spatial distribution of severe convective storms and an analysis of their secular changes. Climate Extremes and Society, H. F. Diaz and R. Murnane, Eds., Cambridge University Press, 35-53.

Bunting, W. F., and B. E. Smith, 1993: A guide for conducting convective windstorm surveys. NOAA Tech. Memo. NWS SR146, Scientific Services Division, Southern Region, Fort Worth, TX, $44 \mathrm{pp}$.

Dessens, J., and J. T. Snow, 1989: Tornadoes in France. Wea. Forecasting, 4, 110-132.

—, and 1993: Comparative description of tornadoes in France and the United States. The Tornado: Its Structure, Dynamics, Prediction and Hazards, Geophys. Monogr., Vol. 79, Amer. Geophys. Union, 427-434.

Doswell, C. A., III, 2007: Small sample size and data quality issues illustrated using tornado occurrence data. Electron. J. Severe Storms Meteor., 2 (5), 1-16.

— , and D. W. Burgess, 1988: On some issues of U.S. tornado climatology. Mon. Wea. Rev., 116, 495-501.

- H. E. Brooks, and N. Dotzek, 2009: On the implementation of the enhanced Fujita scale in the USA. Atmos. Res., 93, 554563.

Dotzek, N., 2001: Tornadoes in Germany. Atmos. Res., 56, 233 251.

— J. Jrieser, and H. E. Brooks, 2003: Statistical modeling of tornado intensity distributions. Atmos. Res., 67, 163-187.

— , P. Groenemeijer, B. Feuerstein, and A. M. Holzer, 2009: Overview of ESSL's severe convective storms research using the European Severe Weather Database ESWD. Atmos. Res., 93, 575-586.

— S. Emeis, C. Lefebvre, and J. Gerpott, 2010: Waterspouts over the North and Baltic Seas: Observations and climatology, predictability and reporting. Meteor. Z., 19, 115-129.

Elsom, D. M., and G. T. Meaden, 1982: Tornadoes in the United Kingdom. Preprints, 12th Conf. on Severe Local Storms, San Antonio, TX, Amer. Meteor. Soc., 55-58.

Feuerstein, B., P. Groenemeijer, E. Dirksen, M. Hubrig, A. M. Holzer, and N. Dotzek, 2011: Towards an improved wind speed scale and damage description adapted for central Europe. Atmos. Res., 100, 547-564.

Forbes, G. S., and R. M. Wakimoto, 1983: A concentrated outbreak of tornadoes, downbursts and microbursts, and implications regarding vortex classification. Mon. Wea. Rev., 111, 220-236.

Fujita, T. T., 1973: Tornadoes around the world. Weatherwise, 26, $56-62$.

- 1981: Tornadoes and downbursts in the context of generalized planetary scales. J. Atmos. Sci., 38, 1511-1534.

Gayá, M., 2011: Tornadoes and severe storms in Spain. Atmos. Res., 100, 334-343.

_ , V. Homar, R. Romero, and C. Ramis, 2001: Tornadoes and waterspouts in the Balearic Islands: Phenomena and environment characterization. Atmos. Res., 56, 253-267.

Giaiotti, D. B., A. Pucillo, and F. Stel, 2007: The climatology of tornadoes and waterspouts in Italy. Atmos. Res., 83, 534-541.

Glickman, T. S., Ed., 2000: Glossary of Meteorology. 2nd ed. Amer. Meteor. Soc., 855 pp.

Golden, J. H., 1973: Some statistical aspects of waterspout formation. Weatherwise, 26, 108-117.

Hales, J. E., Jr., 1988: Improving the watch/warning program through use of significant event data. Preprints, 15th Conf. on
Severe Local Storms, Baltimore, MD, Amer. Meteor. Soc., $165-168$.

Holden, J., and A. Wright, 2004: UK tornado climatology and the development of simple prediction tools. Quart. J. Roy. Meteor. Soc., 130, 1009-1021.

Holzer, A. M., 2001: Tornado climatology of Austria. Atmos. Res., 56, 203-211.

Järvi, L., and Coauthors, 2007: Micrometeorological observations of a microburst in southern Finland. Bound.-Layer Meteor., 125, 343-359.

Kelly, D. L., J. T. Schaefer, R. P. McNulty, and C. A. Doswell III, 1978: An augmented tornado climatology. Mon. Wea. Rev., 106, 1172-1183.

Keränen, J., 1930: Voimakas pyörremyrsky Paltamon Mieslahdella toukok. 27. P:nä 1930 (A strong tornado at Mieslahti in Paltamo on 27th May 1930.) IK, kuukausikatsaus, 24 (11), p. 4.

Leitao, P., 2003: Tornadoes in Portugal. Atmos. Res., 67-68, 381390.

MacGorman, D. R., D. W. Burgess, V. Mazur, W. D. Rust, W. L. Taylor, and B. C. Johnson, 1989: Lightning rates relative to tornadic storm evolution on 22 May 1981. J. Atmos. Sci., 46, 221-251.

Mäkelä, A., P. Rossi, and D. M. Schultz, 2011: The daily cloud-toground lightning flash density in the contiguous United States and Finland. Mon. Wea. Rev., 139, 1323-1337.

Marcinoniene, I., 2003: Tornadoes in Lithuania in the period of 1950-2002 including analysis of the strongest tornado of 29 May 1981. Atmos. Res., 67-68, 475-484.

Minor, J. E., J. R. McDonald, and K. C. Mehta, 1977: The tornado: An engineering-oriented perspective. NOAA Tech. Memo. ERL NSSL-82, National Weather Service, Norman, OK, $196 \mathrm{pp}$.

Newark, M. J., 1984: Canadian tornadoes, 1950-1979. Atmos.Ocean, 22, 343-353.

Outinen, K., and J. Teittinen, 2008: Polarimetric radar observations of a tornadic supercell in Finland. Proc. Fifth European Conf. on Radar in Meteorology and Hydrology, Helsinki, Finland, Finnish Meteorological Institute, P4.3. [Available online at http://erad2008.fmi.fi/proceedings/extended/erad2008-0064extended.pdf.]

Paul, F., 2001: A developing inventory of tornadoes in France. Atmos. Res., 56, 269-280.

Perez, A. H., L. J. Wicker, and R. E. Orville, 1997: Characteristics of cloud-to-ground lightning associated with violent tornadoes. Wea. Forecasting, 12, 428-437.

Peterson, R. E., 1982: Tornadic activity in Europe the last halfcentury. Preprints, 12th Conf. on Severe Local Storms, San Antonio, TX, Amer. Meteor. Soc., 63-66.

_ 1992: Letzmann and Koschmieder's "Guidelines for research on funnels, tornadoes, waterspouts and whirlwinds." Bull. Amer. Meteor. Soc., 73, 597-611.

_ 1995: Johannes Peter Letzmann: Pioneer tornado researcher. Meteorology in Estonia in Johannes Letzmann's Times and Today, H. Eelsalu and H. Tooming, Eds., Estonian Academy Publishers, 9-43.

1998: Tornadoes in Sweden. Preprints, 19th Conf. on Severe Local Storms, Minneapolis, MN, Amer. Meteor. Soc., 89-92. , 2000: Tornadoes of the former Soviet Union. Preprints, 20th Conf. on Severe Local Storms, Orlando, FL, Amer. Meteor. Soc., 138-141.

Punkka, A.-J., and M. Bister, 2005: Occurrence of summertime convective precipitation and mesoscale convective systems in Finland during 2000-01. Mon. Wea. Rev., 133, 362-373. 
_ J. Teittinen, and R. H. Johns, 2006: Synoptic and mesoscale analysis of a high-latitude derecho-severe thunderstorm outbreak in Finland on 5 July 2002. Wea. Forecasting, 21, 752-763.

Rauhala, J., and A.-J. Punkka, 2008: Radar observations of a tornadic severe frontal rainband. Preprints, 24th Conf. on Severe Local Storms, Savannah, GA, Amer. Meteor. Soc., P9.6. [Available online at http://ams.confex.com/ams/24SLS/techprogram/ paper_142151.htm.]

— warnings in Europe. Atmos. Res., 93, 369-380.

Reynolds, D. J., 1999: Revised UK tornado climatology, 19601989. J. Meteor. UK, 24, 290-321.

Rossi, V., and M. Franssila, 1960: Ukkonen ja pyörremyrskyt (Thunderstorm and tornadoes). Oma maa, 8, 54-65.

Setvák, M., M. Salek, and J. Munzar, 2003: Tornadoes within the Czech Republic: From early medieval chronicles to the "internet society." Atmos. Res., 67-68, 589-605.

Simojoki, H., 1931: Pyörremyrsky Wehmersalmella kesäk. 29. p. 1931 (Tornado at Wehmersalmi on 29 June 1931). IK, kuukausikatsaus, 25 (10), p. 4.

_ 1935: Die Tromben am 6. August 1932 im inneren Finnland (Tornado on 6 August 1932 in central Finland). Ann. Acad. Sci. Fenn., 44A, 1-26.

Sioutas, M. V., 2003: Tornadoes and waterspouts in Greece. Atmos. Res., 67-68, 645-656.

- 2011: A tornado and waterspout climatology for Greece. Atmos. Res., 100, 344-356.

Szilard, S., 2007: A systematic approach to synoptic tornado climatology of Hungary for the recent years (1996-2001) based on official damage reports. Atmos. Res., 83, 263-271.

Tarand, A., 1995: How often do tornadoes occur in Estonia? Meteorology in Estonia in Johannes Letzmann's Times and Today, H. Eelsalu and H. Tooming, Eds., Estonian Academy Publishers, 132-138.
Teittinen, J., and A. Mäkelä, 2008: Lightning and radar reflectivity signatures in tornadic supercell thunderstorms in Finland. Proc. Fifth European Conf. on Radar in Meteorology and Hydrology, Helsinki, Finland, Finnish Meteorological Institute, 4 pp. [Available online at http://erad2008.fmi.fi/proceedings/ extended/erad2008-0129-extended.pdf.]

- H. Hohti, J. LaDue, and R. A. Brown, 2006: Analysis of a tornadic mini-supercell in Finland by using Doppler radar. Preprints, 23rd Conf. on Severe Local Storms, St. Louis, MO, Amer. Meteor. Soc., P6.1. [Available online at ams.confex. com/ams/pdfpapers/115430.pdf.]

Tooming, H., 2002: Strong tornadoes in Estonia. Extended Abstracts, European Conf. on Severe Storms 2002, Prague, Czech Republic, Czech Hydrometeorological Institute, p. 33.

- H. Kotli, and R. E. Peterson, 1995: Vigorous tornadoes and waterspouts during the last 35 years in Estonia. Meteorology in Estonia in Johannes Letzmann's Times and Today, H. Eelsalu and H. Tooming, Eds., Estonian Academy Publishers, 168179.

Tuomi, T., and A. Mäkelä, 2007: Lightning observations in Finland, 2007. Finnish Meteorological Institute, Rep. 2007:5, 49 pp.

— and - 2008: Thunderstorm climate of Finland 1998-2007. Geophysica, 44 (1-2), 67-80.

Tuovinen, J.-P., A.-J. Punkka, J. Rauhala, H. Hohti, and D. M. Schultz, 2009: Climatology of severe hail in Finland: 19302006. Mon. Wea. Rev., 137, 2238-2249.

Tyrrell, J., 2003: A tornado climatology for Ireland. Atmos. Res., 67-68, 671-684.

Verbout, S. M., H. E. Brooks, L. M. Leslie, and D. M. Schultz, 2006: Evolution of the U.S. tornado database: 1954-2004. Wea. Forecasting, 21, 86-93.

Wegener, A., 1917: Wind- und Wasserhosen in Europa (Tornadoes and Waterspouts in Europe.) Fredr. Vieweg \& Sohn, $301 \mathrm{pp}$. 